\title{
Comment on 'New-onset type 2 diabetes, elevated HbA1c, anti-diabetic medications, and risk of pancreatic cancer'
}

\author{
Ellena Badrick ${ }^{*}$, , Matthew Sperrin $^{1}$ and Andrew G Renehan ${ }^{1,2}$
}

${ }^{1}$ Center of Health Informatics, Farr Institute@HeRC, Institute of Population Health, University of Manchester, Manchester, UK and ${ }^{2}$ The Christie NHS Foundation Trust, Institute of Cancer Sciences, University of Manchester, Manchester, UK

Sir,

In their paper, Lu et al (2015) correctly stressed the complex relationships between the type 2 diabetes and pancreatic cancer risk. However, their study failed to explicitly define three distinct relationships. In the absence of this framework, their conclusions that 'Newonset type 2 diabetes and .... diabetes with rising HbAlc (levels) seem to be independent risk factors for pancreatic cancer' are misleading. The three relationships are as follows. First, the diagnosis of diabetes and the diagnosis of a new cancer commonly co-occur. This observation is not unique to cancer: the co-occurrence of myocardial infarct and diabetes is well-recognised. The methodological explanation is a detection time or protopathic bias. In data sets where there is standardised recording of cancer diagnosis date, such as in cancer registries, the co-occurrence period is $\sim 12$ months (Johnson et al, 2011), but could be 2 or even 3 years when using, as in this study, first entry of cancer in the primary care records.

Thereafter is the second relationship - the period of longer diabetes exposure and cancer risk. The usual sense of 'risk factor' in epidemiology applies here. As shown in the article's Figure 2, there is no increased pancreatic cancer risk after 2 years. Inclusion of cancers diagnosed shortly after the new-onset diabetes exaggerates the total risk estimate for diabetes-cancer association (Adami et al, 1991). In the period after 2 years, it is conceivable that poor glycaemic control increases incident of cancer - but in the current study, within-person HbAlc levels were missing in $70 \%$ and the authors failed to take account of the well-known $\mathrm{U}$-shaped relationship between HbAlc levels and mortality (Currie et al, 2010). Thus, the conclusions that rising $\mathrm{HbAlc}$ is associated with increased pancreatic cancer incidence are overstated.

The third relationship is the unique existence of pancreatic cancerassociated diabetes (Pannala et al, 2009), where new-onset diabetes might be a clue to early diagnosis of 'silent' pancreatic cancer. Isolated case studies support this hypothesis, but to test in populations, there is a need to map accurately new-onset diabetes with date of diagnosis of asymptomatic pancreatic cancers. This cannot be gleamed from the present data set. Taken together, an alternative interpretation of Lu's analysis might be: 'after excluding cancers detected in the first two years after diabetes diagnosis, there was no association between diabetes and latter pancreatic cancer incidence'.

\section{CONFLICT OF INTEREST}

The authors declare no conflict of interest.

\section{REFERENCES}

Adami HO, McLaughlin J, Ekbom A, Berne C, Silverman D, Hacker D, Persson I (1991) Cancer risk in patients with diabetes mellitus. Cancer Causes Control 2(5): $307-314$

Currie CJ, Peters JR, Tynan A, Evans M, Heine RJ, Bracco OL, Zagar T, Poole CD (2010) Survival as a function of $\mathrm{HbA}(1 \mathrm{c})$ in people with type 2 diabetes: a retrospective cohort study. Lancet 375(9713): 481-489.

Johnson JA, Bowker SL, Richardson K, Marra CA (2011) Time-varying incidence of cancer after the onset of type 2 diabetes: evidence of potential detection bias. Diabetologia 54(9): 2263-2271.

Lu Y, Rodriguez LA, Malgerud L, Gonzalez-Perez A, Martin-Perez M, Lagergren J, Bexelius TS (2015) New-onset type 2 diabetes, elevated HbAlc, anti-diabetic medications, and risk of pancreatic cancer. Br J Cancer 113(11): 1607-1614.

Pannala R, Basu A, Petersen GM, Chari ST (2009) New-onset diabetes: a potential clue to the early diagnosis of pancreatic cancer. Lancet Oncol 10(1): 88-95. 